\title{
Photoswitching neutral homoaromatic hydrocarbons
}

Trung Tran Ngoc ${ }^{\mathrm{a}, \mathrm{c}}$, Niklas Grabicki ${ }^{\mathrm{b}}$, Elisabeth Irran ${ }^{\mathrm{a}}$, Oliver Dumele $\mathrm{b}^{\mathrm{b}^{*}}$ and Johannes F. Teichert $^{\mathrm{c}^{*}}$

a Technische Universität Berlin, Institut für Chemie, Straße des 17. Juni 115, 10623 Berlin, Germany

b Department of Chemistry \& IRIS Adlershof, Humboldt Universität zu Berlin, Brook-Taylor-Straße 2, 12489 Berlin, Germany

c Technische Universität Chemnitz, Institut für Chemie, Fakultät für Naturwissenschaften, Straße der Nationen 62, 09111 Chemnitz, Germany

\section{Abstract}

The identification and characterization of homoaromatic compounds bearing an interrupted $\pi$ system are fundamental challenges for the understanding of electronic interactions in organic molecules. This is further hampered by the fact that no stable neutral homoaromatic hydrocarbon is known. We present the preparation of a new class of neutral homoaromatic compounds, which are supported by experimental evidence (ring current observed by NMR spectroscopy, equalization of bond lengths through X-ray structure analysis) as well as computational analysis (NICS and ACID). Furthermore, we show that one homoaromatic hydrocarbon is a photoswitch through a reversible photochemical [1,11] sigmatropic rearrangement. We provide evidence that the local $6 \pi$ homoaromatic state vanishes upon photoswitching to produce a purely global $10 \pi$ homoaromatic state. These results of stable and accessible homoaromatic neutral hydrocarbons and their photoswitching behaviour provide new insights for the understanding and study of homoconjugative interactions in organic molecules, and for the design of new responsive molecular materials.

\section{Introduction}

Homoaromatic molecules display characteristics of aromatic stabilization yet possess an interrupted cyclic conjugated $\pi$-system ${ }^{1}$. The concept of homoaromaticity, resting upon through-bond or through-space homoconjugation ${ }^{2,3}$ (the interaction between disconnected $\pi$ - 
systems, usually interrupted by one or more $\mathrm{sp}^{3}$-hybridized carbon atoms ${ }^{1,4}$ ) has been highly controversial in the past ${ }^{1}$. The difficulty to identify clear criteria for the assignment of molecules as homoaromatic at first ${ }^{1,5}$ as well as the small number of known homoaromatic molecules further spurred the discussion in this field.

The generally accepted criteria ${ }^{1,4}$ include (I) one or more homoconjugative interactions (through-space or through-bond); (II) electron delocalization due to effective overlap of $\pi$ orbitals; (III) delocalization of $(4 n+2) \pi$-electrons in a partially cyclic structure; (IV) bond length equalization of single and/or double bonds; (V) magnetic characteristics associated with "normal aromaticity" and (VI) resonance stabilization energy.

Several ionic homoaromatic compounds have been disclosed ${ }^{6-8}$; however, examples for neutral homoaromatic molecules (especially purely organic ones) remain extremely rare ${ }^{9-}$ 15. In fact, besides a few heteroatom-containing molecules ${ }^{9-11,15}$, no undisputed neutral homoaromatic hydrocarbon has been synthesized or isolated to date ${ }^{12-14}$, spurring the comment in the leading review that "there remains a dearth of neutral homoaromatics"1.

The simplest homoaromatic analogue of benzene with a potential through-space homoconjugation, cycloheptatriene 1, has been discussed as prototypical homoaromatic (Fig. 1, top $)^{1,3,16-18}$. Calculations indicate a homoaromatic character; however, no experimental data exist to support this claim $^{19}$. For the prototypical through-bond homoaromatic norcaradiene 2 , calculations show no indication for homoaromaticity ${ }^{19}$.

Topic of a long-standing debate about homoaromaticity in neutral molecules was elassovalene $3^{20,21}$, which represents a potentially neutral $10 \pi$-electron homoaromatic. However, after independent preparation of $\mathbf{3}$ by the groups of Paquette and Vogel, evaluation of spectral data, magnetic criteria, and finally comparison to related aromatic annulenes, it was concluded that elassovalene 3 is not a neutral homoaromatic hydrocarbon ${ }^{20,22-26}$. Therefore, the quest for a neutral homoaromatic hydrocarbon still remains. The group of Quast came close to this goal when they found that for barbaralane-derivative $\mathbf{4}$ the homoaromatic transition state was markedly stabilized in selected polar solvents ${ }^{27-30}$, however, in the crystal structure of $\mathbf{4}$, only limited bond length equalization was observed (see below, Fig. 4) rendering this 
molecule the closest candidate for a neutral homoaromatic hydrocarbon so far. An isolable, truly homoaromatic hydrocarbon thus far has remained elusive.

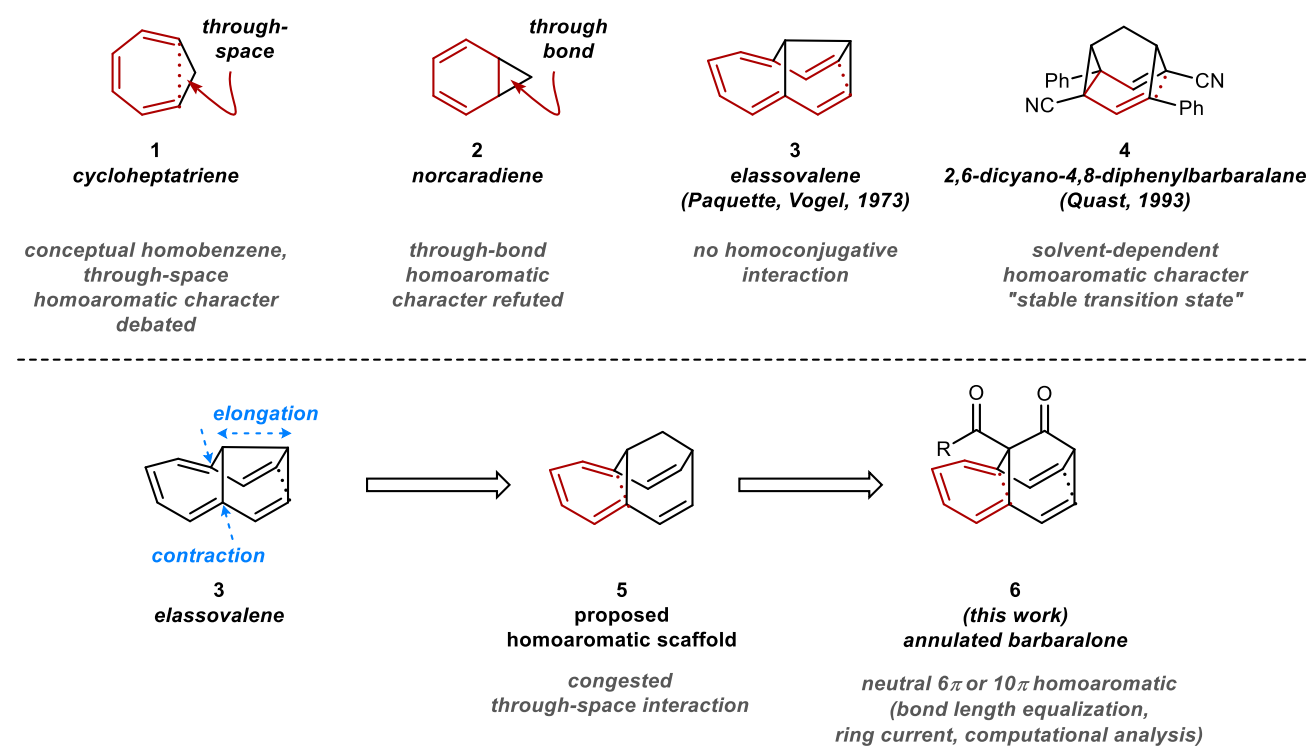

Fig. 1 | Examples of potentially neutral homoaromatic compounds/Rational approach to neutral homoaromatics.

The abovementioned examples underscore the required combined computational and experimental evidence for the assignment of a homoaromatic electronic structure. However, structural information is difficult to access, since neutral homoaromatics are often transient species $^{1,13,14,29}$ and not crystalline, hampering the identification of bond length equalization as one of the key criteria for homoaromaticity. We herein present the synthesis of a neutral class of homoaromatic hydrocarbons, homoannulenes 6, and discuss its homoaromaticity, supported by experimental data (chemical shifts from NMR spectroscopy and bond length comparison from X-ray structure elucidation) and calculations. We further show that compounds 6 act as a structurally novel photochemical switch through an unprecedented reversible photo-induced $[1,11]$ sigmatropic rearrangement forming a novel neutral $10 \pi$ homoaromatic.

\section{Results and Discussion}

Our working hypothesis to design stable and isolable neutral homoaromatics emanated from elassovalene 3 (Fig. 1, bottom). Extending the bridging unit from a semibullvalene to a barbaralane core as in $\mathbf{5}$, we anticipated that an additional carbon atom in the bridge would 
allow for more structural flexibility and thus would facilitate the interaction of both ends of the $\pi$-system through-space to allow for homoconjugative interaction ${ }^{31}$. At the same time, the target molecule would in principle bear both a potential $6 \pi$ as well as a $10 \pi$ homoaromatic system, allowing to probe larger homoaromatic interactions.

We targeted the synthesis of a potentially $6 \pi$ - or $10 \pi$-electron homoaromatic homoannulene 6 with a barbaralone-derived framework (Fig. 2, bottom). For the related bridged aromatic annulenes ${ }^{32-34}$, semibullvalenes ${ }^{20,34}$ and elassovalene ${ }^{20} \mathbf{3}$ (Fig. 2, top), Vogel had emanated from tetrahydronaphthalenes $\mathbf{7}$ or hexahydroanthracenes, respectively, employing the central alkene(s) of hydrogenated polyaromatic compounds such as tetrahydronaphthalene as synthetic linchpin for a key cyclopropanation (Fig. 2a, inside $\rightarrow$ outside). We envisioned an orthogonal approach (outside $\rightarrow$ inside), utilizing first the outer disubstituted alkene of the related dihydronaphthalene $\mathbf{8}$, leaving the benzene ring untouched. In this manner, we could circumvent the inherent higher reactivity of the central tetrasubstituted alkene for the key cyclopropanation, and exploited a challenging intramolecular dearomative Buchner reaction as central methodology in the synthesis ${ }^{25}$.

In this vein, we first reduced naphthalene 9 to 1,4-dihydronaphthalene 8, making the outer double bond accessible for the subsequent rhodium(II) catalyzed cyclopropanation ${ }^{35}$, giving cyclopropane 10 as a diastereomeric mixture of trans-10 and cis-10 (2:1). Separation of the two isomers trans-10 and cis-10 was achieved by iterative temperature-dependent saponification with $\mathrm{KOH}$ exploiting the innate reactivity difference of the diastereomeric cyclopropyl esters trans-10 and cis-10: a first saponification with $\mathrm{KOH}$ at room temperature selectively transformed trans-10 to the trans-11 acid and thus facilitated removal of unwanted trans isomer. Raising the temperature from room temperature to reflux afforded the all-ciscarboxylic acid cis-11 through subsequent saponification under elevated temperature. In allcis-11, the carboxylic acid is aligned suitably towards the benzene ring, a key necessity for the downstream intramolecular Buchner reaction. It should be noted that this particular Buchner reaction is further impeded by the fact that acetoacetate-derived diazo compounds generally display significantly lower reactivity in cyclopropanation reactions ${ }^{25}$. We continued by activation 
of all-cis-11 and chain elongation by Claisen condensation to form acetoacetate 12 . Subsequent diazo transfer reaction led to the corresponding diazo compound 13. The following intramolecular Buchner reaction, vital for our outside $\rightarrow$ inside strategy, required excessive catalyst optimization: After investigation of a variety of $\mathrm{Rh}(\mathrm{II})$ and $\mathrm{Cu}$ (II) complexes, we identified $\mathrm{Cu}(\mathrm{hFacac})_{2}$ as suitable catalyst for the desired Buchner dearomatization to give triasterane 14 (for optimization see Supporting Information). Remarkably, only few of the catalysts employed gave the desired product 14 at all, whereas the Buchner reaction catalyzed by $\mathrm{Cu}(\mathrm{hFacac})_{2}$ did not show any traces of otherwise competing $\mathrm{C}-\mathrm{H}$-insertions. Finally, dehydrogenative oxidation using DDQ gave homoannulene ester 15. To support the connectivity and stereochemistry of the desired products, crystal structures were obtained for $11,12 b-14 b$ and $15^{36}$. Gratifyingly, this allowed for analysis of bond lengths with foresight to potential homoaromaticity (see below).

When exploring the general chemical reactivity of 15 , we found that saponification conditions unexpectedly led to the formation of the rearranged homoannulene carboxylic acid 16 (for a proposed mechanism, see the Supplementary Figure 3). This turned out to be a fortunate discovery, as $\mathbf{1 6}$ not only represents yet another neutral homoaromatic compound, but with the X-ray crystal structure of $\mathbf{1 6}$ available, it also serves as key reference compound for the following investigation of the magnetic properties of the neutral homoaromatics 15 and 16. 

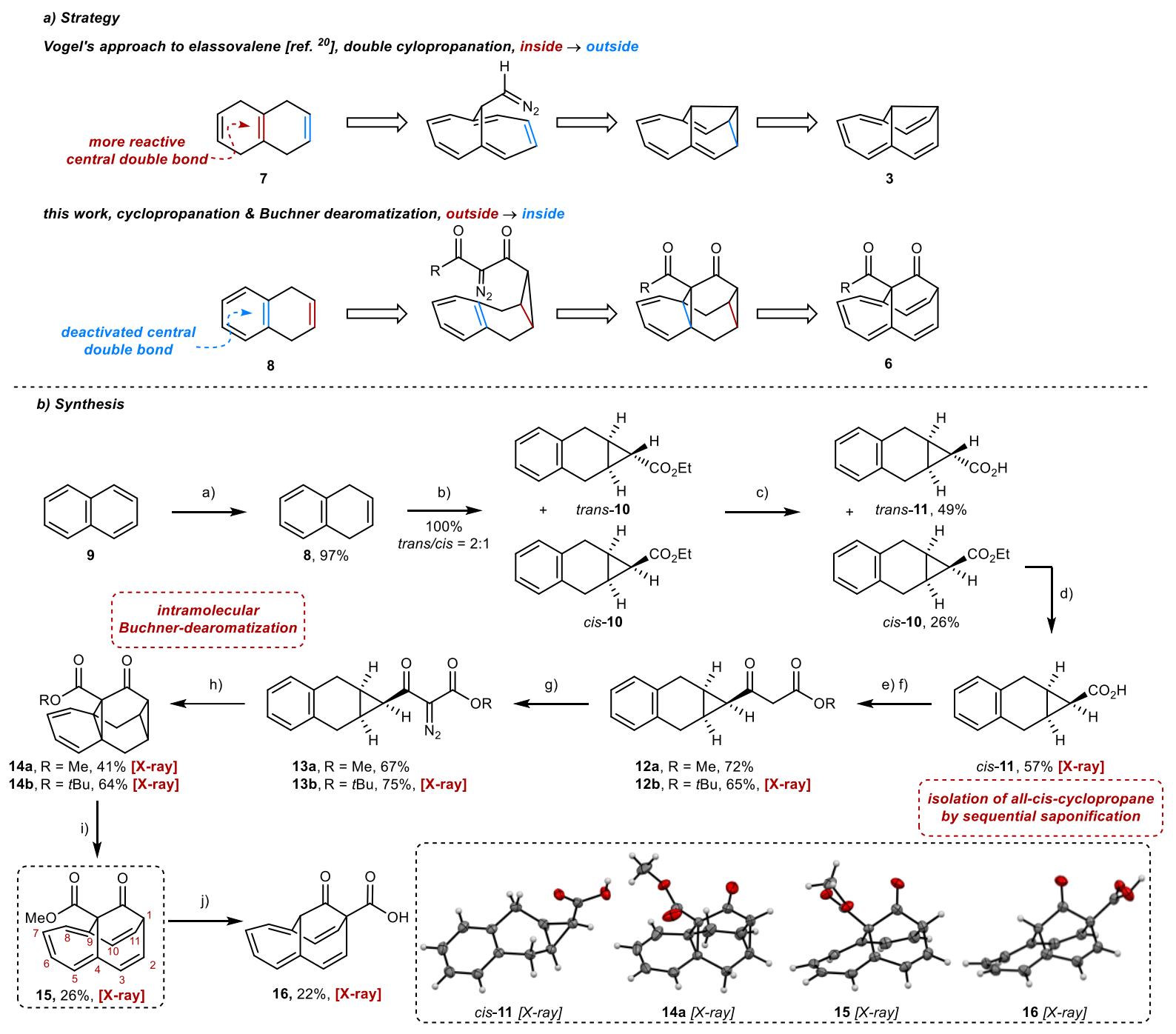

Fig. 2 | Synthesis of homoannulene ester 15. Conditions: a) 2.5 equiv $\mathrm{Na}, 2.5$ equiv $t \mathrm{BuOH}$, $\mathrm{Et}_{2} \mathrm{O}, 21{ }^{\circ} \mathrm{C}, 14 \mathrm{~h}$; b) 1.5 equiv ethyl diazoacetate, $1.0 \mathrm{~mol} \% \mathrm{Rh}_{2}(\mathrm{OAc})_{4}, \mathrm{CH}_{2} \mathrm{Cl}_{2}, 21^{\circ} \mathrm{C}, 20 \mathrm{~h}$; c) 3.0 equiv $\mathrm{KOH}, \mathrm{EtOH}, 21{ }^{\circ} \mathrm{C}, 8 \mathrm{~h}$; d) 3.0 equiv $\mathrm{KOH}$, $\mathrm{EtOH}$, reflux, $3 \mathrm{~h}$; e) 1.0 equiv carbonyldiimidazol, THF, $21^{\circ} \mathrm{C}, 1 \mathrm{~h}$; f) 2.5 equiv AcOMe or AcOtBu, 5.0 equiv LDA, THF, -78 to $\left.21{ }^{\circ} \mathrm{C}, 3 \mathrm{~h} ; \mathrm{g}\right) 1.1$ equiv 4 -acetamidobenzenesulfonyl azide, 1.1 equiv $\mathrm{Et}_{3} \mathrm{~N}, \mathrm{MeCN}, 0$ to $21^{\circ} \mathrm{C}, 3 \mathrm{~h}$; h) $10 \mathrm{~mol} \% \mathrm{Cu}(\mathrm{hFacac})_{2} \cdot \mathrm{xH}_{2} \mathrm{O}, \mathrm{C}_{6} \mathrm{H}_{5} \mathrm{Cl}$, reflux, $3 \mathrm{~h}$; i) 2.0 equiv DDQ, $\mathrm{C}_{6} \mathrm{H}_{5} \mathrm{Cl}$, $130{ }^{\circ} \mathrm{C}, 4 \mathrm{~h}$; j) 4.0 equiv $\mathrm{KOH}, \mathrm{MeOH} / \mathrm{H}_{2} \mathrm{O}(1: 1), 21^{\circ} \mathrm{C}, 27 \mathrm{~h}$.

Homoannulene ester 15 and the rearranged homoannulene carboxylic acid 16 turned out to be ideal probes for the investigation of magnetic properties (induced ring current) indicative for a homoaromatic interaction ${ }^{1}$. Magnetic anisotropy and susceptibility of homoaromatic compounds is verifiable by NMR spectroscopy through marked chemical shifts ${ }^{1,37-40}$. Comparing the ${ }^{1} \mathrm{H}$ NMR spectra of $14 a, 15$ and 16 (Fig. 3), we observed that 15 and 16 display a significant down-field shift of hydrogen atoms 5 and 6 of $\sim 1.00 \mathrm{ppm}$ as compared to $14 a$, giving a first indication of the presence of a ring current in the former two. 
Furthermore, the $\alpha$-carbonyl methine group of homoannulene ester 15 , facing away from the potential homoaromatic system, displays an expected chemical shift of $\delta=3.81 \mathrm{ppm}$ (Fig. 3, top). In stark contrast, the $\alpha$-carbonyl methine ${ }^{1} \mathrm{H}$ NMR resonance of homoannulene carboxylic acid 16, placed directly above the homoaromatic system, is significantly shifted up-field to $\delta=0.89 \mathrm{ppm}$, although being placed directly adjacent an electron-withdrawing ketone (Fig. 3, bottom). Even taking the anisotropic effect of the double bonds into account ${ }^{16}$, this unusually high up-field shift of $\Delta \delta=2.92 \mathrm{ppm}$ unambiguously indicates the presence of a diamagnetic ring current ${ }^{39,41}$, which shields the methine hydrogen of $16^{16,32}$. Both key spectral properties (downfield shift of hydrogen atoms 5 and 6 and shift of bridgehead methine hydrogen) are missing in elassovalene $(3)^{20,23}$, whose analogous methine hydrogen appears at $\delta=1.77 \mathrm{ppm}$ (and $\mathrm{C}_{\mathrm{sp} 2}-\mathrm{H}$ appear at 6.30 and $6.64 \mathrm{ppm}$, respectively). Homoannulene ester 15 as well as homoannulene carboxylic acid 16 possess an interrupted cyclic $\pi$ system. The observation of a strong ring current therefore indicates the existence of through-space interaction of the $\pi$ system leading to a delocalization of $\pi$-electrons ${ }^{2}$. Therefore, the fused barbaralone framework prepared in this study seems to structurally enable an efficient homoconjugation by an elongated bridge that facilitates the through-space interaction of carbon atoms $C(4) \cdots C(9)$ through steric congestion. Combined, these findings serve as important indication that homoannulene ester 15 and homoannulene carboxylic acid 16 are neutral homoaromatic compounds. 


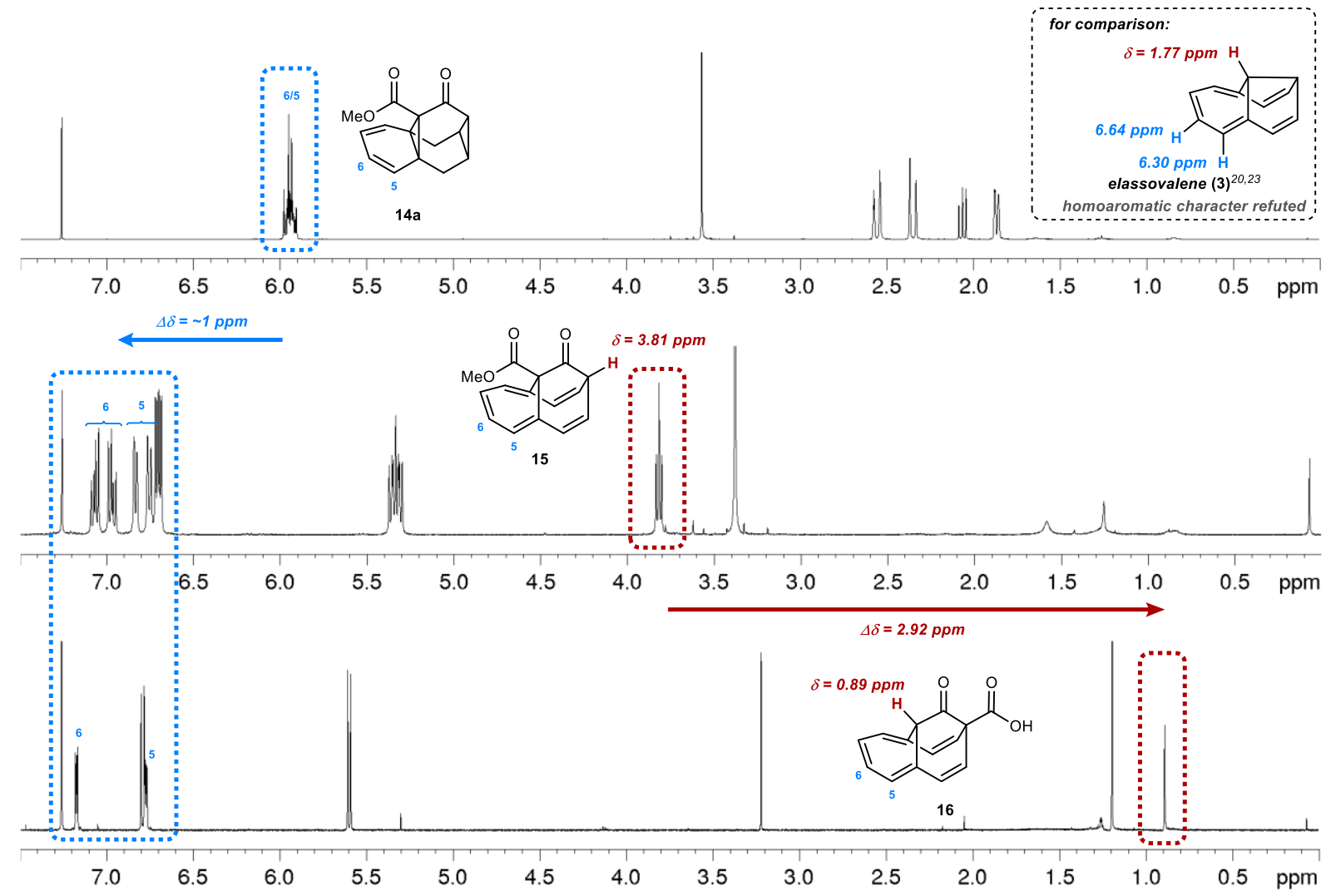

Fig. 3 | Comparison of the ${ }^{1} \mathrm{H}$ NMR chemical shifts of triasterane $14 \mathrm{a}$, homoannulene ester 15 and annulene carboxylic acid 16 (400 MHz, $\left.\mathrm{CDCl}_{3}, 298 \mathrm{~K}\right)$.

One of the paramount characteristics for homoaromatic compounds is bond length equalization of the single and double bonds involved ${ }^{1,2}$. With the $X$-ray structures of 14,15 and 16 available for detailed analysis, we observed significant shortening of the single bonds and elongation of the double bonds (Fig. 4). As limits, bond lengths of isolated C-C-single (1.54 $\mathrm{A})$ and $\mathrm{C}=\mathrm{C}$-double bonds $(1.34 \AA$ ) as well as the "ideal" bond length equalization of benzene $(1.39 \AA)$ are considered for comparison ${ }^{42}$. These values are compared to the longest $\mathrm{C}-\mathrm{C}$ single bond and the shortest $\mathrm{C}=\mathrm{C}$-double bond, respectively, of the respective neutral homoaromatic molecules 14a, 15 and 16 (see the Supplementary Figure 2 for detailed analysis of all bond lengths).

For homoannulene ester 15, a homoaromatic cycloheptatrienyl fragment seems to be present as indicated by the bond length equalization (shortest double bond is $1.364 \AA$ (Fig. 4, red arrows) and the longest single bond is $1.420 \AA$ long (Fig. 4, blue arrows)). The formal vinyl substituents in the barbaralone substructure show alternating (single and double) bond lengths 
(ca. 1.45 and ca. $1.34 \AA$, respectively), indicating a $6 \pi$ homoaromatic compound with two vinyl substituents. Also, for homoannulene carboxylic acid 16, equalized bond lengths are observed (1.428 and $1.360 \AA$ for longest $\mathrm{C}-\mathrm{C}$-single and shortest $\mathrm{C}=\mathrm{C}$-double bond in the cycloheptatriene moiety). In contrast, non-oxidized triasterane 14a displays the expected bond length alternation for a 1,3-diene and lacks any indication for homoconjugation. We compared our observations to Quast's barbaralane $4^{28-30}$ (Fig. 4), which to our knowledge shows the most neutral homoaromatic properties reported so $\operatorname{far}^{1}$ (1.459 and $1.347 \AA$ for longest C-C-single and shortest $\mathrm{C}=\mathrm{C}$-double bond). Homoannulene ester 15 and carboxylic acid 16 show significantly higher bond length equalization than barbaralane 4 . Indeed, the bond length equalization observed for $\mathbf{1 5}$ and $\mathbf{1 6}$ is rather comparable to Vogel's methano[10]annulene $\mathbf{1 7}^{32}\left(1.372-1.419 \AA^{43}\right)$, which is considered aromatic ${ }^{32,44}$. The bond length equalization of 15 and $\mathbf{1 6}$ in addition to the ring current observation discussed above lead us the conclusion that 15 and 16 are indeed the first examples of truly neutral homoaromatic compounds.

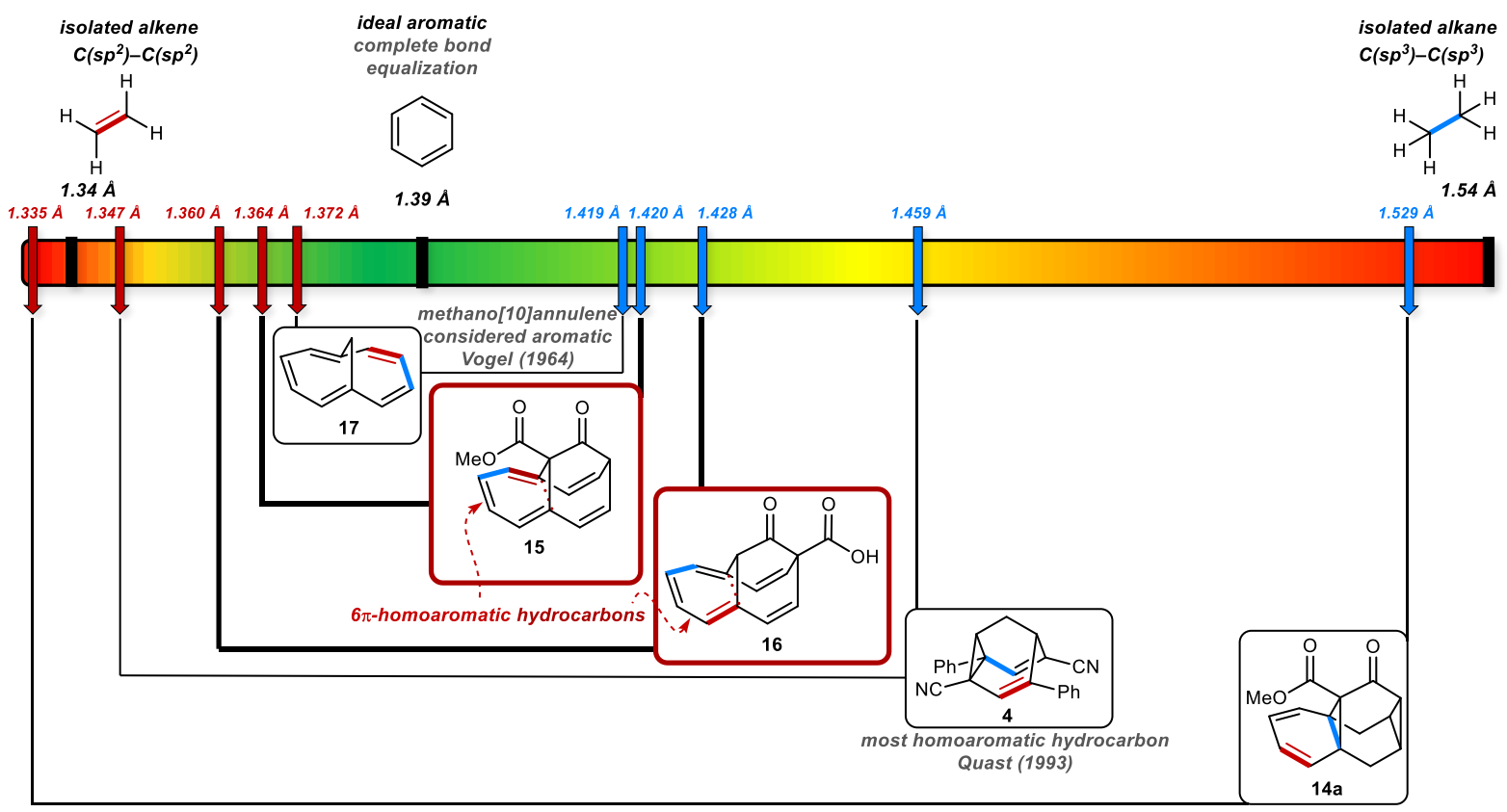

Fig. 4 | Bond length comparison from X-ray diffraction. Shortest double bond (red arrows) and longest single bond (blue arrows) of the (homo)aromatic part of methano[10]annulene $(17)^{32,43}$, barbaralane 4 by Quast ${ }^{28-30}$, triasterane $14 a$, homoannulene ester 15 and homoannulene carboxylic acid 16.

Extended conjugated $\pi$-systems - especially aromatic ones - express particular reactivity and show the ability to absorb energy in the UV/vis range. To further elucidate the homoaromatic 
character of $\mathbf{1 5}$ we investigated its behavior upon irradiation with light, as has been done for several other homoaromatic compounds $20,27,28,45$. We found that homoannulene ester 15 undergoes a photoinduced rearrangement of the barbaralone framework forming ester 18 (305 nm LED irradiation for $80 \mathrm{sec}$ of a dilute cyclohexane or MeCN solution of 15, Fig. 5a). The thermal stability of photoproduct $\mathbf{1 8}$ was verified by heating the photostationary state (PSS) mixture obtained at $305 \mathrm{~nm}$ in $\mathrm{MeCN}$ for $9.25 \mathrm{~h}$ at $55^{\circ} \mathrm{C}$ without any noticeable change in composition (see Supplementary Figures 13 and 14). Therefore, compounds 15 and 18 could be separated using preparative HPLC chromatography. Full characterization of $\mathbf{1 8}$ using NMR spectroscopy and HR-MS analysis allowed the unambiguous determination of its structure. The formation of 18 can be rationalized by an unprecedented [1,11] sigmatropic rearrangement from 15 to 18 , which is suprafacially allowed under photochemical conditions in accordance with the Woodward-Hoffman rules ${ }^{46}$. UV/vis spectroscopy indicates a clean rearrangement, supported by the HPLC traces and the isosbestic points observed (Fig. 5b and c). Integration of the peak areas of the UV/vis-HPLC traces revealed a ratio 15/18 of $30: 70$ at the PSS (see Supplementary Fig. 10). This photochemical reaction was found to be independent of solvent polarity and could not only be observed in cyclohexane but equally rapid in $\mathrm{MeCN}$, supportive of a non-polar transition state typically observed for pericyclic reactions (see Supplementary Fig. 7).

Photochromic systems are of special interest in the development of functional materials ${ }^{47}$. Prediction and rational design of new photochromic motifs that can be reversibly switched from one state into another by light has proven challenging. Attempting the backreaction of 18 to 15 , we found that the photochemical [1,11] sigmatropic rearrangement is reversible upon irradiation with a $455 \mathrm{~nm}$ LED light source. This renders homoannulene ester 15 a structurally novel photochemical switch ${ }^{48-50}$. The photochromic system can be classified as a $p$-type photoswitch (backreaction photochemically activated).

We performed multiple cycles of irradiation alternating between a $305 \mathrm{~nm}$ and $455 \mathrm{~nm}$ LED (Fig. 5b). Although the irradiation repeatedly led to the formation of $\mathbf{1 8}$ in the PSS and backformation of $\mathbf{1 5}$, analysis of the UV/vis absorption maxima at $390 \mathrm{~nm}$ over several cycles 
indicated a moderate switching fatigue caused by the formation of trace side products in the photoswitching process (see Supplementary Fig. 11). We hypothesize that the formation of rearranged 18 is driven by a homoaromatic stabilization effect and thus turned our attention to the computational electronic and magnetic structure analysis of 15 and 18.

a)
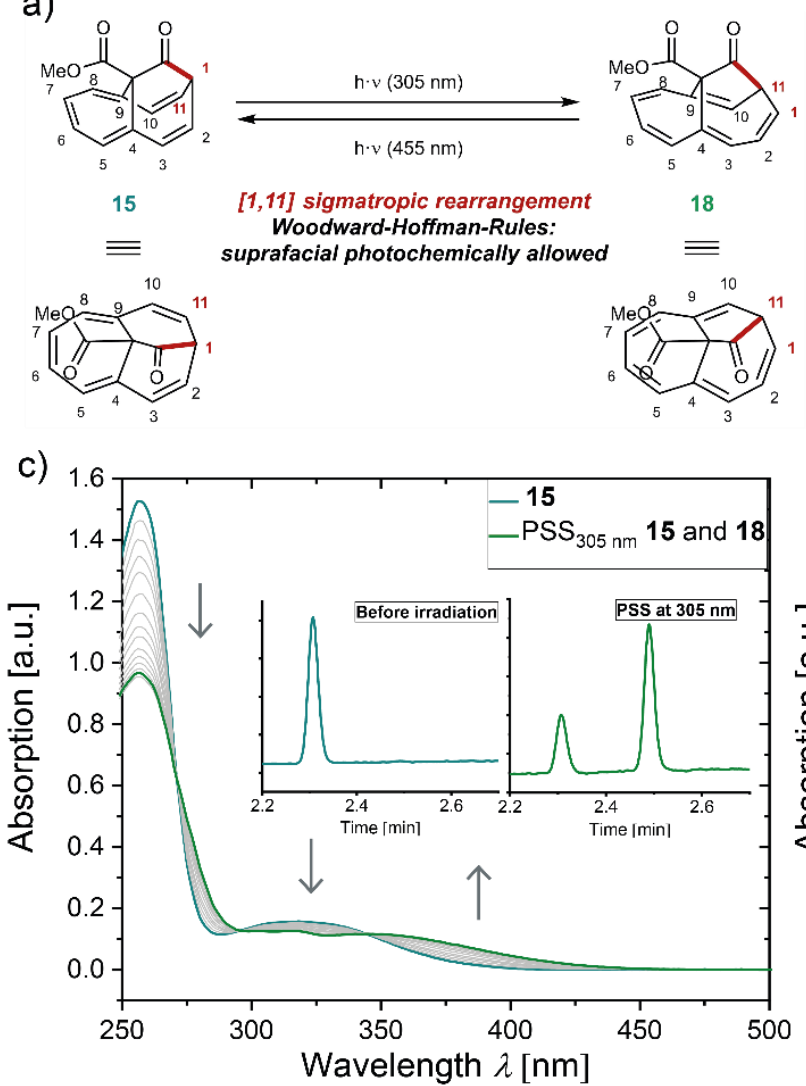

b)

d)
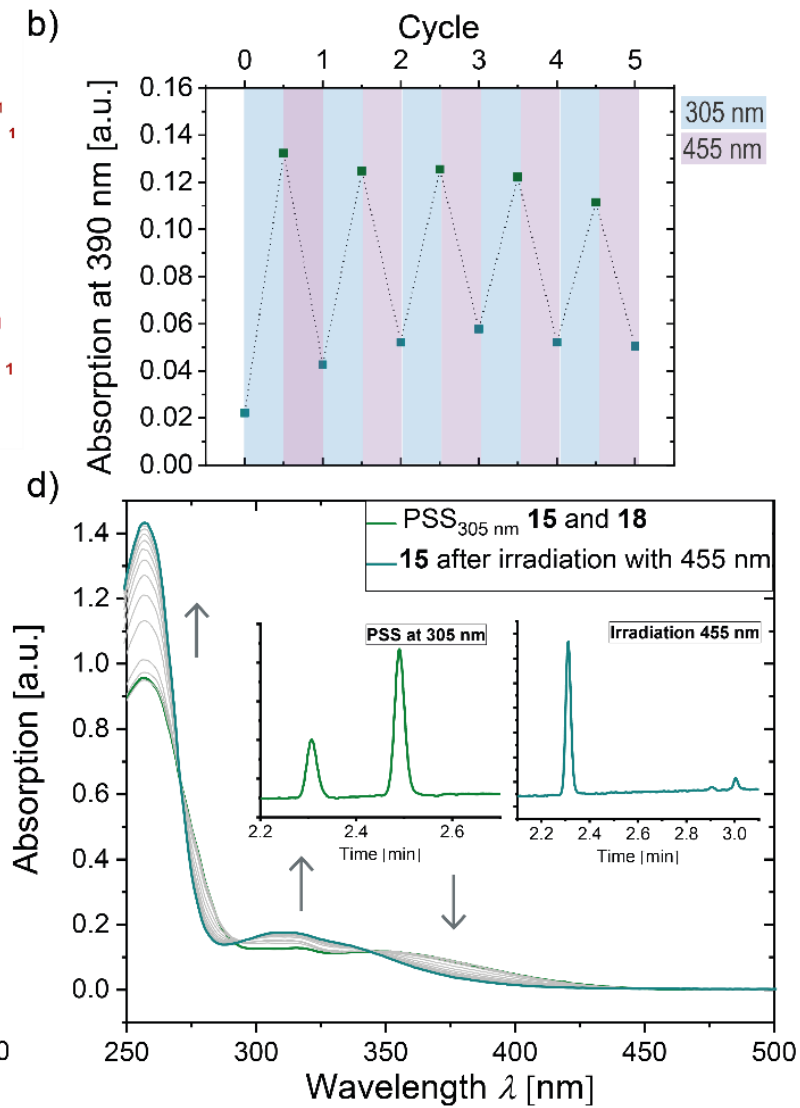

Fig. 5 | Photoswitchable $[1,11]$ sigmatropic rearrangement ${ }^{46}$. a) Homoannulene ester 15 undergoes reversible $[1,11]$ sigmatropic rearrangement ${ }^{46}$ at $\lambda=305 \mathrm{~nm}$ to ester 18 (only one possible enantiomer displayed) and back-reaction to 15 at $\lambda=455 \mathrm{~nm}$; b) Cycling experiments of the photoreaction. Absorbance at $390 \mathrm{~nm}$ shown under alternating irradiation between $305 \mathrm{~nm}$ (blue shaded) and $455 \mathrm{~nm}$ (red shaded); c) UV/vis absorption of 15 (cyan) in cyclohexane $\left(c(15)=5.5 \times 10^{-5} \mathrm{~mol} \mathrm{~L}^{-1}\right)$ upon irradiation with a $305 \mathrm{~nm}$ LED (grey, every $5 \mathrm{~s}$, $80 \mathrm{~s}$ total) and till the PSS $_{305 \mathrm{~nm}}$ is reached (green); d) back-irradiation into 15 using a $455 \mathrm{~nm}$ LED (grey, spectra recorded every $60 \mathrm{~s}, 11 \mathrm{~min}$ total). Insets show HPLC chromatograms at the start and end of the irradiation.

The induced ring currents of (homo)aromatic systems by an external magnetic field were probed computationally as a measure for the homoaromaticity of $\mathbf{1 5}$ and $\mathbf{1 8}$. In conjunction with (indirect) experimentally determined diatropicity via ${ }^{1} \mathrm{H}$ NMR spectroscopy for the adjacent hydrogen atoms, magnetic indices can be used to theoretically correlating the degree of 
aromaticity. Two such magnetic indices that are widely used are nucleus independent chemical shifts (NICS) $)^{51-54}$ and the anisotropy of the induced ring current density (ACID) ${ }^{55,56}$, which were calculated for 15 and 18 (Fig. 6 and Supplementary Discussion Section 1.7).

To simplify the calculations, the methyl ester groups in $\mathbf{1 5}$ and $\mathbf{1 8}$ were replaced by methyl groups (now: Me-15, Me-18). Due to the non-planar $\pi$ ring geometry we calculated NICS $z z$ values at various distances greater than $1.7 \AA$ below the ring centroids to avoid contaminations of $\sigma$-bond-induced ring currents ${ }^{53,54}$. These one- and two-dimensional NICS $\mathrm{zz}_{\mathrm{zz}}$ scans of Me-15 (Fig. 6a, c) reveal a pronounced diatropic ring current of the $\mathrm{C}(4)$ to $\mathrm{C}(9)$ fragment of $\mathbf{M e - 1 5}$ with NICS $(1.8)_{z z}$ values reaching down to $-18.6 \mathrm{ppm}$. In contrast, the adjacent ring current in the $\mathrm{C}(2-4) \cdots \mathrm{C}(9-11)$ fragment is only moderately diatropic with less negative $\mathrm{NICS}(1.8)_{\mathrm{zz}}$ values of $-12.5 \mathrm{ppm}$. In contrast, upon $[1,11]$ sigmatropic rearrangement to 18 , the diatropic ring currents are equalized over the $10 \pi$ system of Me-18 with similar NICS $(1.8)_{z z}$ values of $11.3 \mathrm{ppm}$ and $-15.2 \mathrm{ppm}$ for the six- and seven-membered fragments, respectively. Finally, the plotted ACID underscores the conjugation paths of the ring currents unambiguously (Fig. $6 e, f)^{55,56}$. A significant homoaromatic through-space interaction for Me-15 can be observed between atoms $\mathrm{C}(2)$ and $\mathrm{C}(11)$ at a critical isosurface value (CIV) of 0.034 supporting a global $10 \pi$ homoaromatic character in agreement with the NICS analysis of $\mathbf{1 5}$ (in comparison, the CIV for non-planar cycloheptatriene $\mathbf{1}$ is 0.027 at the same level of theory $\left.{ }^{55,56}\right)$. A second through-space interaction between $\mathrm{C}(4)$ and $\mathrm{C}(9)$ is observed at a CIV of 0.026 indicating a local $6 \pi$ homoaromatic ring current in $\mathbf{1 5 .}$

For $\mathbf{1 8}$ the situation is changed again, where a through-space interaction is observed between $\mathrm{C}(1)$ and $\mathrm{C}(10)$ at a CIV of 0.040 , indicating an enhanced global $10 \pi$ homoaromaticity. On the contrary, no through-space interaction can be observed for the local $6 \pi$-system between $\mathrm{C}(4)$ and C(9) even at an CIV as low as 0.01 (see Supplementary Fig. 26). We conclude that both 15 and 18 are globally $10 \pi$ homoaromatic with an enhanced local homoaromaticity in the $6 \pi$ system of 15 and a nearly equalized $10 \pi$ homoaromatic state in $\mathbf{1 8}$. The latter is due to geometric constraints originating from the rearranged scaffold in 18, allowing for efficient homoconjugation between $\mathrm{C}(1)$ and $\mathrm{C}(10)$ that facilitates a $10 \pi$ electron ring current. 

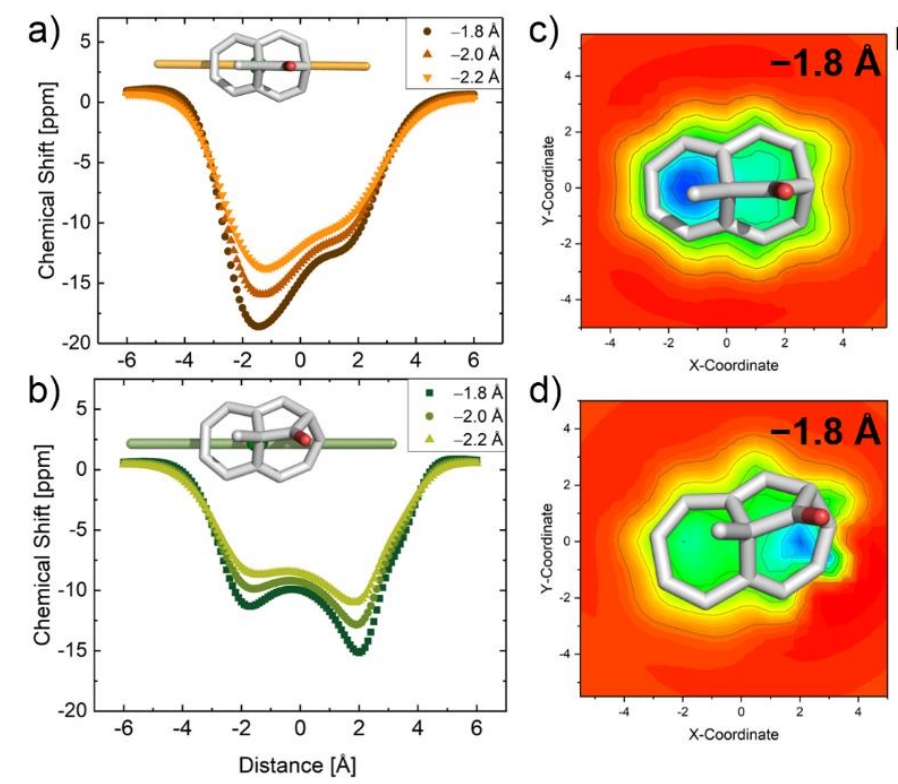

d)

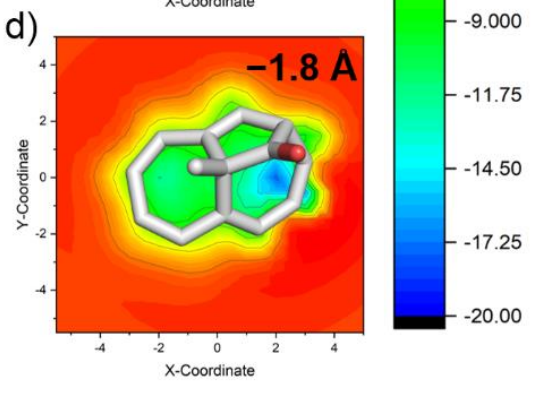

e)
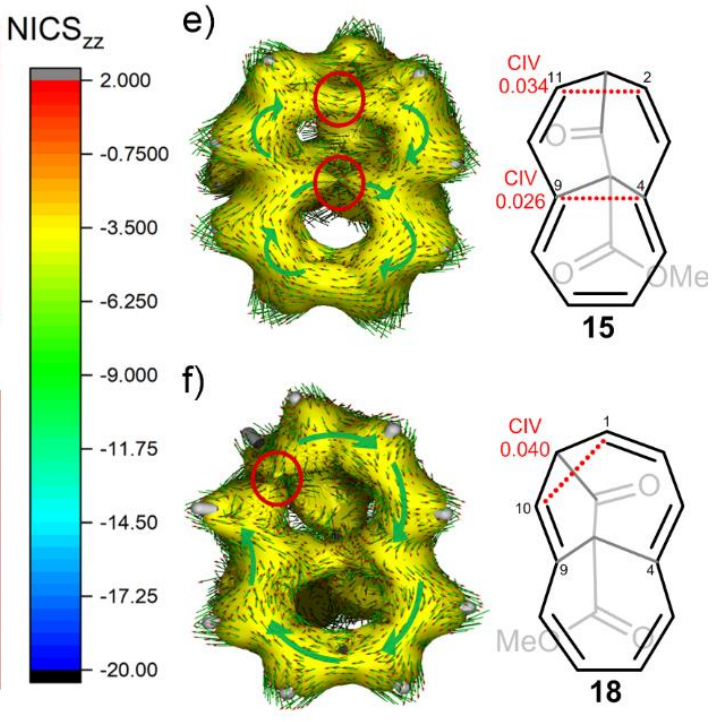

Fig. 6 | Computational evaluation of homoaromaticity in Me-15 and Me-18. NICS $\mathrm{zz}_{\mathrm{z}}-\mathrm{XY}$ scan below the ring centroid at distances of $1.8 \AA$, $2.0 \AA, 2.2 \AA$, a) Me-15, b) Me-18; NICS $\mathrm{zz}^{-}$ $\mathrm{XY}$ heat map $1.8 \AA$ below the ring centroid of $\mathrm{c}$ ) Me-15 and d) Me-18 (the region of the blue area in (d) originates from the close proximity of the carbon skeleton near $C(1,2)$ to the NICS probe; scale of the color code in ppm; e) ACID plot of Me-15 at an isosurface-value of 0.026 and f) ACID plot of Me-18 at an isosurface value of 0.040, with through-space interactions highlighted with red circles and the depicted vector field (arrows) of anisotropically induced ring currents. The external magnetic field is aligned orthogonal to the ring planes pointing towards the reader.

\section{Conclusion}

Assigning molecules as homoaromatic has been a long-standing problem since molecules with sufficient stability and lifetime were elusive. We herein describe the synthesis of homoannulene ester 15 and the related acid 16, the first isolated neutral homoaromatic hydrocarbons. Their homoaromatic state was evidenced by ${ }^{1} \mathrm{H}$ NMR spectroscopic data indicating a significant ring current in addition to a high degree of bond length equalization in the X-ray crystal structures. A detailed computational analysis by means of NICS scans and ACID isosurface plots revealed the ring currents and conjugation pathways. The local $6 \pi$ homoaromatic state of homoannulene ester 15 can be photoswitched at $300 \mathrm{~nm}$ to a purely global $10 \pi$ homoaromatic state by an unprecedented photochemical $[1,11]$ sigmatropic rearrangement to ester 18. This photoreaction is reversible and irradiation of $\mathbf{1 8}$ at $455 \mathrm{~nm}$ 
yields back homoannulene $\mathbf{1 5}$. Therefore, $\mathbf{1 5 / 1 8}$ is a conceptually and structurally novel photoswitch, targeting different homoaromaticity states. Notably, both 15 and 18 exhibit high thermal stability and thus the photochemical switch does not suffer from thermal background reactions. The interconvertible homoannulenes $15 \leftrightarrows \mathbf{1 8}$ are the first neutral and isolable homoaromatic hydrocarbons and represent a new functional platform of molecular photoswitches based on homoaromatic stabilization effects.

\section{Data availability}

Crystallographic data have been deposited at the Cambridge Crystallographic Data Centre (http://www.ccdc.cam.ac.uk/) under CCDC numbers 2128305, 2128302, 2128309, 2128304, $2128306,2128303,2128308,2128307,2133482$. These data can be obtained free of charge via https://www.ccdc.cam.ac.uk/structures/. All other data supporting the findings of this study are available within the paper and its Supplementary Information.

\section{References}

1. Williams, R. V. Homoaromaticity. Chem. Rev. 101, 1185-1204 (2001).

2. Cremer, D., Childs, R. F. \& Kraka, E. Cyclopropyl Homoconjugation, Homoaromaticity and Homoantiaromaticity-Theoretical Aspects and Analysis. In The chemistry of the cyclopropyl group, edited by Z. Rappoport (Wiley, Chichester, 1995), Vol. 2, pp. 339-410.

3. Childs, R. F., Cremer, D. \& Elia, G. Cyclopropyl Homoconjugation-Experimental Facts and Interpretations. In The chemistry of the cyclopropyl group, edited by Z. Rappoport (Wiley, Chichester, 1995), Vol. 2, pp. 411-468.

4. Fernandez, I. (ed.). Aromaticity. Modern computational methods and applications (Elsevier, S.I., 2021).

5. Winstein, S. Homo-aromatic Structures. J. Am. Chem. Soc. 81, 6524-6525 (1959). 
6. Schuppan, J., Herrschaft, B. \& Müller, T. The Elusive 7-Silanorbornadien-7-ylium: Synthesis and Characterization of Nitrilium and Oxonium lons Deriving from 2,3-Benzo-7silanorbornadien-7-ylium. Organometallics 20, 4584-4592 (2001).

7. Scheschkewitz, D., Hofmann, M., Ghaffari, A., Amseis, P., Präsang, C., Mesbah, W., Geiseler, G., Massa, W. \& Berndt, A. Very strong anionic homoaromaticity in (deloc1,3,4)-1-sila-3,4-diboracyclopentane-1-ides, the importance of the energy of the reference system for homoaromatic stabilization energies. J. Organomet. Chem. 646, 262-270 (2002).

8. Sahin, Y., Ziegler, A., Happel, T., Meyer, H., Bayer, M. J., Pritzkow, H., Massa, W., Hofmann, M., Schleyer, P. v. R., Siebert, W. \& Berndt, A. Two-electron homoaromatics with heteroatom bridges. J. Organomet. Chem. 680, 244-256 (2003).

9. Präsang, C., Amseis, P., Scheschkewitz, D., Geiseler, G., Massa, W., Hofmann, M. \& Berndt, A. Strong Neutral Homoaromatics. Angew. Chem. Int. Ed. 45, 6745-6747 (2006). and references therein.

10. Wehrmann, R., Klusik, H. \& Berndt, A. Strong 1,3-Interaction in 1,2-Dihydroboretes: Homoborirenes. Angew. Chem. Int. Ed. Engl. 23, 369-370 (1984).

11. Freeman, P. K. Neutral Homoaromaticity in Some Heterocyclic Systems. J. Org. Chem. 70, 1998-2001 (2005).

12. Hrovat, D. A., Brown, E. C., Williams, R. V., Quast, H. \& Borden, W. T. How important is bishomoaromatic stabilization in determining the relative barrier heights for the degenerate Cope rearrangements of semibullvalene, barbaralane, bullvalene, and dihydrobullvalene? J. Org. Chem. 70, 2627-2632 (2005).

13. Freeman \& Pugh. Homoaromaticity in carbene intermediates. J. Org. Chem. 65, 6107$6111(2000)$.

14. Freeman, P. K. \& Pugh, J. K. The Chemistry of 2-Carbenabicyclo[3.2.1]octadiene: An AbInitio Molecular Orbital Study. J. Am. Chem. Soc. 121, 2269-2273 (1999). 
15. Jemmis, E. D., Phukan, A. K., Jiao, H. \& Rosenthal, U. Structure and Neutral Homoaromaticity of Metallacyclopentene, -pentadiene, -pentyne, and -pentatriene: A Density Functional Study. Organometallics 22, 4958-4965 (2003).

16. Paquette, L. A. The Realities of Extended Homoaromaticity. Angew. Chem. Int. Ed. Engl. 17, 106-117 (1978).

17. Vogel, E. Perspektiven der Cycloheptatrien-Norcaradien-Valenztautomerie. Pure Appl. Chem. 20, 237-262 (1969).

18. Nyulászi, L. \& Schleyer, P. v. R. Hyperconjugative m-Aromaticity: How To Make Cyclopentadiene Aromatic. J. Am. Chem. Soc. 121, 6872-6875 (1999).

19. Chen, Z., Jiao, H., Wu, J. I., Herges, R., Zhang, S. B. \& Schleyer, P. v. R. Homobenzene: homoaromaticity and homoantiaromaticity in cycloheptatrienes. J. Phys. Chem. A 112, 10586-10594 (2008).

20. Vogel, E., Brinker, U. H., Nachtkamp, K., Wassen, J. \& Müllen, K. Semibullvalenes as Potential Homoaromatic Compounds. Angew. Chem. Int. Ed. Engl. 12, 758-760 (1973).

21. Paquette, L. A., Wingard, R. E. \& Russell, R. K. Structural consequences of 2,8 bridging of the semibullvalene nucleus. J. Am. Chem. Soc. 94, 4739-4741 (1972).

22. Wenkert, E., Hagaman, E. W., Paquette, L. A., Wingard, R. E. \& Russell, R. K. Carbon-13 nuclear magnetic resonance spectral analysis of semibullvalene and related substances. J. Chem. Soc., Chem. Commun., 135 (1973).

23. Paquette, L. A., Liao, C. C., Burson, R. L., Wingard, R. E., Shih, C. N., Fayos, J. \& Clardy, J. Synthesis and electronic properties of 2a,8b-dihydrocyclopent[cd]azulenes (elassovalenes). J. Am. Chem. Soc. 99, 6935-6945 (1977).

24. Günther, H., Schmickler, H., Brinker, U. H., Nachtkamp, K., Wassen, J. \& Vogel, E. Significance of Stereochemical Factors for the Chemical Shift of the $13 \mathrm{C}$ Resonance. Angew. Chem. Int. Ed. Engl. 12, 760-761 (1973). 
25. Vogel, E. \& Reel, H. Bent [14]annulenes. Synthesis of 1,6:8,13-

ethanediylidene[14]annulene. J. Am. Chem. Soc. 94, 4388-4389 (1972).

26. Dewey, H. J., Deger, H., Froelich, W., Dick, B., Klingensmith, K. A., Hohlneicher, G., Vogel, E. \& Michl, J. Excited states of methano-bridged [10]-, [14]-, and [18]annulenes. Evidence for strong transannular interaction, and relation to homoaromaticity. J. Am. Chem. Soc. 102, 6412-6417 (1980).

27. Seefelder, M. \& Quast, H. Solvent Effects on the Equilibrium between Localized and Delocalized States of Thermochromic Semibullvalenes and Barbaralanes. Angew. Chem. Int. Ed. 38, 1068-1071 (1999).

28. Quast, H. \& Seefelder, M. The Equilibrium between Localized and Delocalized States of Thermochromic Semibullvalenes and Barbaralanes-Direct Observation of Transition States of Degenerate Cope Rearrangements. Angew. Chem. Int. Ed. 38, 1064-1067 (1999).

29. Quast, H., Geißler, E., Herkert, T., Knoll, K., Peters, E.-M., Peters, K. \& Schnering, H. G. von. 2,6-Dicyan-4,8-diphenylbarbaralan. Chem. Ber. 126, 1465-1475 (1993).

30. Quast, H., Seefelder, M., Peters, E.-M. \& Peters, K. Synthesis, Crystal Structure, and Circular Dichroism Spectra of (1S)-4,8-Diphenylbarbaralane-2,6-dicarbonitrile Chiroptical Properties of the Transition State of a Degenerate Cope Rearrangement. Eur. J. Org. Chem. 1999, 1811-1823 (1999).

31. Williams, R. V., Al-Sehemi, A. G., Meier, A. K., Brown, Z. Z. \& Armantrout, J. R. The Role of Strain in the Homoaromatization of Semibullvalenes. J. Org. Chem. 82, 4136-4147 (2017).

32. Vogel, E. \& Roth, H. D. The Cyclodecapentaene System. Angew. Chem. Int. Ed. Engl. 3, 228-229 (1964).

33. Vogel, E., Sturm, W. \& Cremer, H.-D. 1,6:8,13-Butanediylidene[14]annulene. Angew. Chem. Int. Ed. Engl. 9, 516-517 (1970). 
34. Vogel, E., Vogel, A., Kübbeler, H.-K. \& Sturm, W. 1,6:8,13-

Propanediylidene[14]annulene. Angew. Chem. Int. Ed. Engl. 9, 514-516 (1970).

35. Doyle, M. P. Catalytic methods for metal carbene transformations. Chem. Rev. 86, 919939 (1986).

36. cis-11: CCDC 2128305; 12b: CCDC 2128302; 13b: CCDC 2128309; 14a: CCDC 2128304; 14b: CCDC 2128306; 15: CCDC 2128303; 16: CCDC 2128308; S9: CCDC 2128307.

37. Lazzeretti, P. \& Zanasi, R. Theoretical studies of the benzene molecule: Magnetic susceptibility and nuclear shielding constants. J. Chem. Phys. 75, 5019-5027 (1981).

38. Childs, R. F., McGlinchey, M. J. \& Varadarajan, A. Ring currents, NMR chemical shifts, and homoaromaticity: the homotropylium ion revisited. J. Am. Chem. Soc. 106, $5974-$ $5978(1984)$.

39. Gershoni-Poranne, R. \& Stanger, A. Magnetic criteria of aromaticity. Chem. Soc. Rev. 44, $6597-6615(2015)$

40. Schleyer, P. v. R. \& Jiao, H. What is aromaticity? Pure Appl. Chem. 68, 209-218 (1996).

41. Gomes, J. A. \& Mallion, R. B. Aromaticity and ring currents. Chem. Rev. 101, 1349-1383 (2001).

42. The HOMA-index (Harmonic Oscillator Model of Aromaticity) has also been used for the description of bond length equilibration: Krygowski, T. M., Szatylowicz, H., Stasyuk, O. A., Dominikowska, J. \& Palusiak, M. Aromaticity from the viewpoint of molecular geometry: application to planar systems. Chem. Rev. 114, 6383-6422 (2014). See the Supporting Information for HOMA-indices of molecules discussed here.

43. Bianchi, R., Pilati, T. \& Simonetta, M. Structure of 1,6-methano[10]annulene. Acta Cryst. B 36, 3146-3148 (1980). 
44. Caramori, G. F., Oliveira, K. T. de, Galembeck, S. E., Bultinck, P. \& Constantino, M. G. Aromaticity and Homoaromaticity in Methano[10]annulenes. J. Org. Chem. 72, 76-85 (2007).

45. Paquette, L. A., Watson, T. J., Friedrich, D., Bishop, R. \& Bacque, E. Is Through-Bond Dihydroaromaticity Attainable? Preparation of [4,5]Dihomotropone, Investigation of Its Ground-State Properties, and an Attempt to Generate the Dihomotropylium Cation. J. Org. Chem. 59, 5700-5707 (1994).

46. Spangler, C. W. Thermal [1,j] sigmatropic rearrangements. Chem. Rev. 76, 187-217 (1976).

47. Goulet-Hanssens, A., Eisenreich, F. \& Hecht, S. Enlightening Materials with Photoswitches. Adv. Mater. 32, e1905966 (2020).

48. Bléger, D. \& Hecht, S. Visible-Light-Activated Molecular Switches. Angew. Chem. Int. Ed. 54, 11338-11349 (2015).

49. Crespi, S., Simeth, N. A. \& König, B. Heteroaryl azo dyes as molecular photoswitches. Nat. Rev. Chem. 3, 133-146 (2019).

50. Feringa, B. L. \& Browne, W. R. Molecular switches. 2nd ed. (Wiley-VCH, Weinheim, Germany, 2011).

51. Schleyer, P. v. R., Maerker, C., Dransfeld, A., Jiao, H. \& van Eikema Hommes, N. J. R. Nucleus-Independent Chemical Shifts: A Simple and Efficient Aromaticity Probe. J. Am. Chem. Soc. 118, 6317-6318 (1996).

52. Chen, Z., Wannere, C. S., Corminboeuf, C., Puchta, R. \& Schleyer, P. v. R. Nucleusindependent chemical shifts (NICS) as an aromaticity criterion. Chem. Rev. 105, 38423888 (2005).

53. Gershoni-Poranne, R. \& Stanger, A. The NICS-XY-scan: identification of local and global ring currents in multi-ring systems. Chem. Eur. J. 20, 5673-5688 (2014). 
54. Stanger, A. Nucleus-independent chemical shifts (NICS): distance dependence and revised criteria for aromaticity and antiaromaticity. J. Org. Chem. 71, 883-893 (2006).

55. Geuenich, D., Hess, K., Köhler, F. \& Herges, R. Anisotropy of the induced current density (ACID), a general method to quantify and visualize electronic delocalization. Chem. Rev. 105, 3758-3772 (2005).

56. Herges, R. \& Geuenich, D. Delocalization of Electrons in Molecules. J. Phys. Chem. A 105, 3214-3220 (2001).

\section{Acknowledgements}

Prof. Dr. Martin Oestreich (TU Berlin) and Stefan Hecht (HU Berlin) are kindly thanked for their generous support. Dr. Sebastian Kemper (TU Berlin) and Dr. André Dallmann (HU Berlin) are thanked for assistance with the NMR experiments. This research was funded by the Deutsche Forschungsgemeinschaft (DFG, German Research Foundation) under Germany's Excellence Strategy EXC 2008-390540038-UniSysCat: T.T.N. receives funding through the cluster of excellence Unifying Concepts in Catalysis. O.D. acknowledges the support of the Fonds der Chemischen Industrie (FCl) through a Liebig scholarship and N.G. thanks the FCl for a doctoral scholarship.

\section{Author information}

Contributions: T.T.N. carried out the synthesis and characterization studies. T.T.N. solved the crystal structures with assistance of I.E.. T.T.N. and N.G. carried out the photochemical studies. N.G. did the quantum chemical calculations. J.F.T. conceived the concept. O.D. and J.F.T. directed the research. All the authors contributed to the analysis of the results and the writing of the manuscript. 
Corresponding author: Correspondence and requests for materials should be addressed to J.F.T. (johannes.teichert@chemie.tu-chemnitz.de) and O.D. (oliver.dumele@hu-berlin.de).

\section{Ethics declarations}

The authors declare no competing interests.

\section{Supplementary Information}

Experimental procedures and characterization data. Supplementary discussion, Figs. 1-26, Tables 1-21, spectra 1-134 and references 1-23.

\section{Supplementary Data}

Crystallographic data as cif files. 
